\title{
Airline Pricing Behaviour Under Limited Intermodal Competition*
}

\author{
Angela S. Bergantino ${ }^{\dagger} \quad$ Claudia Capozza ${ }^{\ddagger}$
}

November 15, 2012

\begin{abstract}
This paper explores airline pricing behaviour dealing with two issues. The first is to measure the extent to which intramodal competition influences fares charged to travellers. The second is to shed light on fares' intertemporal profile to verify if airlines undertake intertemporal price discrimination (IPD) strategies and whether IPD is of monopolistic-type or competitive-type. Differently from past contributions, we study airline pricing behaviour removing the influence of intermodal competition. To this scope, we focus on the southern Italian market since it is less accessible by other modes and thus, air transport-related competition prevails. Our results claim that when the intramodal competition reduces, airlines apply higher fares as they exploit the greater market power arising from more concentrated market structure. Further, we find evidence that airlines do undertake IPD strategies - the intertemporal profile of fares follows a J-curve - but that they do so in more competitive markets.

Key words: airfares, market structure, intertemporal price discrimination

JEL: L11, L13, L93
\end{abstract}

*Special thanks to Marco Alderighi, Richard Arnott, Michele Bernasconi, Volodymyr Bilotkach, André de Palma, Alberto Gaggero, Andrew Goetz, Kai Hüschelrath, Marc Ivaldi and Claudio Piga for useful comments and insights on earlier versions. The authors would also like to thank participants at 39th EARIE Conference, 14th SIET Conference, RCEA Workshop on "The economics and management of leisure, travel and tourism" and 32th AISRe Conference for very helpful comments and suggestions. All remaining errors are ours.

$\dagger$ University of Bari "Aldo Moro", email: angelastefania.bergantino@uniba.it.

†University of Bari "Aldo Moro", email: claudia.capozza@uniba.it. 


\section{Introduction}

There are three sources of competition in the airline markets. Airlines compete with other airlines for the same city-pair markets (intramodal competition). Moreover, airlines compete with other modes of transport (intermodal competition) as trains, especially high speed trains, and cars, which give the advantage to travel at any time. Finally, airlines compete with themselves by setting different fares in different time periods prior to departure (intertemporal price discrimination). As a consequence, airline pricing behaviour is jointly affected by all these competitive forces.

Past empirical contributions explored airline pricing behaviour and how market structure influence it. However, they were not able to control for the effect of intermodal competition which, we can expect, affected the results. This paper differs from existing works as it attempts to study airline pricing behaviour removing the influence of intermodal competition in order to shed light on airline pricing behaviour in response to the pure air-related competition. To this scope, we choose to analyse a market, southern Italy, which definitely shows a highly limited intermodal competition. For peripherical areas, air transport is, often, the only realistic alternative, therefore airline pricing strategies are the straight results of air-related competition.

This work explores airline pricing behaviour focusing on two basic issues. The first is to measure the extent to which intramodal competition - captured by market structure indexes - influences fares charged to travellers. The second is to shed light on the intertemporal profile of fares to verify if airlines undertake intertemporal price discrimination (IPD) strategies and whether IPD is of monopolistic-type or competitive-type. The former type implies that market power enhances the ability of firms to price discriminate (Tirole, 1988); the latter type implies that market power is not required to sustain price discrimination if consumers show heterogeneity of brand preferences (Borenstein, 1985 and Holmes, 1989) or demand uncertanty about departure time (Dana, 1998; 1999).

The dataset used, covering routes that originates in southern Italy and are operated from November 2006 to February 2011, is unique. Data on posted fares were collected from airline website by replicating real travellers' behaviour when making 
reservations. Unlike previous contributions, we use round-trip fares instead of oneway fares. This way, we effectively simulate travellers' behaviour since travellers use to purchase round trip tickets rather than one way tickets ${ }^{1}$. Besides, we can accurately define the market structure as we can precisely identify carriers' supply (i.e. if it is a feasible alternative for the traveller and thus if the carrier is a competitor). Finally, Full Service Carriers (FSCs) usually charge round-trip fares lower than the sum of two one-way fares. This policy is not adopted by Low Cost Carriers (LCCs), hence, to avoid distorsions, previous contributions limit the empirical analysis to LCCs or to a few carries. Instead, we do not encounter this problem, thus we are able to carry out a market analysis and compare pricing behaviour of all carrier types.

Our results on a market with no substitute goods (i.e. no alternative modes of transport) highlight that when the intramodal competition reduces, airlines apply higher fares since they exploit the greater market power arising from more concentrated market structure. Specifically, a 10\% increase of market concentration allows carriers to price up to $6.7 \%$. Moreover, we find evidence of a non-monotonic (Jshaped) intertemporal profile of fares consistent with the implementation of IPD strategies. Gaggero (2010) suggests that the non-monotonicity reflects a pattern opposite to that of travellers' demand elasticity while, Bilotkach et al (2012), assert that a fare drop responds to the need of raising the load factor. Although we share these arguments, our claim is that the non-monotonicity of fares' intertemporal profile is also the evidence that airlines exploit consumers' bounded rationality. In effect, a common wisdom among travellers is "the later you buy, the more you pay the ticket", thus price sensitive consumers tend to buy in advance. Being aware of this, airlines can extract their surplus by posting moderatly higher fares for very-early purchasers that will buy tickets believing to pay the cheapest fares. Finally, we provide evidence of a "competitive-type" IPD as airlines appear to be more likely to undertake IPD in more competitive markets.

The reminder of the paper unfolds as follows. In Section 2 we survey the relevant literature. The data collection is described Section 3. In Section 4 we present the

\footnotetext{
${ }^{1}$ See, for instance, the analysis on airline travel demand carried out by Belobaba (1987).
} 
empirical strategy and in Section 5 we illustrate the robustness check. Then, in Section 6 we discuss the results and in Section 7 we draw conclusions.

\section{Literature review}

This section aims at reviewing the literature on airline pricing behaviour following the main goals of this paper. On the one side, we discuss contributions which analyse the effect of airline market structure on fares; on the other side, we survey contributions which focus on IPD and, also, on its relationship with market structure.

The liberalisation of the airline market, that took place in the late 1970s in US and involved the European markets in the late 1990s, stimulated the research on air transportation. A bulk of literature explored the impact of market structure on average fares charged to travellers. The first study was Borenstein (1989) on US the airline industry that developed a model in which market share at both route and airport level was used. The results indicate that either market share on the route or at the airports influences carrier's ability to raise fares since the dominant presence of an airline at an airport increases its market share on routes included in that airport. However, Evans and Kessides (1993) claim that, when controlling for inter-route heterogeneity, market share on the route does not influece anymore fares; instead, market share at the airports is the decisive factor which affects fares. More recently, some contributions explored the European airline markets. Differently from the US market, Carlsson (2004) claims that market power, measured with the Herfindahl index, does not have a significant effect on fares whereas it influences flight frequencies. Consistently, Giaume and Guillou (2004) find a negative and, often, non significant impact of market concentration in intra European routes (from Nice Airport (France) to European destinations) on fares. Bachis and Piga (2007a) measure the effect of market concentration, computed at the origin airport, at the route and the city-pair level, on fares applied by British carriers. Their results reveal that a carrier with a greater martket share on a route sets higher fares while a carrier with a greater market share on a city-pair does not appear to set higher fares, thus revealing the existence of a large degree of substitutability between the routes in 
a city-pair. Finally, Gaggero and Piga (2010) find that higher market share and Herfindhal Index at the city-pair level leads to higher fares on routes connecting the Republic of Ireland to the UK.

As far as concerns IPD, Logfren (1971) argues there IPD when a seller plans pricing strategy for two periods, thus applying, for the same good, higher prices to consumers with higher purchasing power in the first period and lower prices to consumers with lower purchasing power in the second period. The main difference between static and intertemporal price discrimination is that two different markets are coverd in the former case whereas the same market is periodically covered in the latter case. More generally, Stokey (1979) claims that IPD occurs when goods are "introduced on the market at a relatively high price, at which time they are bought only by individuals who both value them very highly and are very impatient. Over time, as the price declines, consumers to whom the product is less valuable or who are less impatient make their purchases". Goods falling into this category are, for instance, books, movies, computers and related programmes. In the airline industry, IPD consists of setting different fares for different travellers according to the days missing to departure when the ticket is bought. By using IPD, airlines exploit travellers' varied willingness to pay and demand uncertainty about departure time: price-inelastic consumers, usually business travellers, use to purchase tickets close to departure date, whereas price-elastic consumers, usually leisure travellers, tend to buy tickets in advance ${ }^{2}$. While in other markets prices are usually decreasing along the time, in the airline market the intertemporal profile of fares is, usually, increasing due to advance-purchase discounts, as shown by some theoretical contributions. Gale and Holmes (1992) prove that the advance-purchase discount is an efficient means of allocating capacity by spreading consumers across peak and off-peak flights when the peak is unknown. They show that low-cost-time consumers purchase in advance, paying lower fares. Moreover, Gale and Holmes (1993) demostrate that a monopoly airline can increase the output by smoothing demand of consumers with weak time

\footnotetext{
${ }^{2}$ Travellers' heterogeneity appears to be a necessary condition to successfully implement price discrimination strategies. A theoretical contribution of Alves and Barbot (2009) illustrates that low-high pricing is a dominant strategy for low cost carriers only if travellers, on a given route, show varied willingness to pay.
} 
preferences over flight times through advance-purchase discounts, thus extracting high-time-cost travellers' surplus. Finally, Dana (1998) claims that when consumers are heterogeneous in both their valuations and their demand uncertainty, the pattern of advance-purchase discounts is due to consumers with low valuations that are more likely to buy in advance.

The intertemporal profile of fares has been also empirically explored. Bachis and Piga (2007a) show that fares posted by British low cost carriers follow an increasing intertemporal profile consistent with the pursuing of an intertemporal price discrimination strategy. Instead, Bachis and Piga (2007b), who examined UK fares to and from Europe, and Alderighi and Piga (2010), that focused on fares posted by Ryanair in the UK market, indicate that the temporal profile appears to be U-shaped. In addition, Gaggero and Piga (2010), who analysed the routes connecting Ireland and UK, illustrate that fares' intertemporal pattern of individual flights follows a J-curve. Gaggero (2010) explains the non monotonic intertemporal profile of fares as follows. He identifies three main categories of travellers: early-bookers and middle-bookers, usually leisure travellers, and late-bookers, mostly business travellers. Early bookers show a slightly inelastic demand: as families planning holidays, they are willing to pay moderately higher fares to travel during vacations. Middle-bookers exhibit the highest demand elasticity: they are more flexible and search for the cheapest fares. Late-bookers reveal an inelastic demand: a business traveller typically books tickets only a few days before the departure, with fixed travel dates and destination. As a result, airline fares display a non-monotonic trend over time whose shape resembles a J-curve and reflects a pattern opposite to that of travellers' demand elasticity. First, airlines set the initial level of fares that then decrease as more price-sensitive travellers begin to shop, until they reach the minimum. Afterward, fares steadily increase as the departure date approaches ${ }^{3}$.

One strand of literature explores the relationship between market structure and price discrimination to find out whether the employment of price discrimination

\footnotetext{
${ }^{3}$ Abrate et al (2010) show that even in the hotel industry, hoteliers undertake IPD strategy with two opposite trends. If a room is booked for the working days, last minute prices are lower; instead if a room is reserved for the weekend, last minute prices are higher.
} 
strategies decreases or increases when markets become more competitive. Traditionally market power enhances the ability of firms to price discriminate: a monopolist can set and maintain higher mark-ups ${ }^{4}$. In the oligopolistic airline industry, when competition increases, carriers lose this ability: mark-ups associated with the fares paid by the less price-sensitive (business) travellers decrease and align with the ones of the more price-sensitive (leisure) travellers.

However, travellers differ in their degree of brand loyalty: while business travellers opt for the long-run savings given by loyalty programmes ${ }^{5}$, leisure travellers disregard carriers since they prefer the short-run savings from paying lower fares. When competition increases, the mark-ups applied to leisure travellers decrease, whereas the mark-ups applied to business travellers remain almost unchanged: price discrimination increases as competition increases. Theoretical contributions demonstrate that price discrimination can be implemented even in competitive markets. Borenstein (1985) and Holmes (1989) show that market power is not required to sustain price discrimination if consumers show heterogeneity of brand preferences. Sorting consumers based on strength of brand preference is a successful strategy and competition does not prevent firms from pursuing it. Further, Gale (1993) mantains that competition to conquer less time-sensitive travellers is stronger in an oligopoly than in a monopoly: it reduces fares on the lower end of the distribution, thus causing price dispersion. Dana (1998) shows that price discrimination in the form of advance purchase discounts, does not require market power to be implemented: consumers with more certain demands are willing to buy in advance because the presence of consumers with less certain demands could lead to an increase in prices. Finally, Dana (1999) demonstrates that prices become more dispersed as markets become more competitive.

As far as concerns the empirical studies, part of the literature has adopted the approach of Stavins (2001) that identifies price discrimination by the ticket restrictions.

\footnotetext{
${ }^{4}$ See Tirole (1988) chapter 3.

${ }^{5}$ Borenstein (1989) analyses the role of loyalty programmes. Concentration increases fares and such an effect is markedly greater for the 80th percentile. This is due to the Frequent Flyer Programs (FFPs) generally joined by business travellers. When market power increases, airlines increase fares and, relying on the loyalty created by FFPs, they increase the fares paid by business travellers more.
} 
Other contributions have followed the approach of Boreinstein and Rose (1994) who interpret price dispersion as a result of price discrimination.

Stavins (2001) provides evidence that in the US airline industry, price discrimination is enforced to a greater extent when markets are more competitive: ticket restrictions ${ }^{6}$ reduce fares although the effect is reduced in more concentrated markets. Giaume and Guillou (2004) take up the cross-sectional model of Stavins (2001) and explore the intra-European market defined by flights from Nice (France) to European destinations, getting to the same result ${ }^{7}$.

In line with Stavins (2001), Borenstein and Rose (1994) explore the US airline industry to show that price discrimination strategies are used more by airlines in more competitive markets: lower price dispersion arises in more concentrated markets. The analysis of Borenstein and Rose (1994) was revisited by Gerardi and Shapiro (2009). First, they replicated the cross-sectional analysis of Borenstein and Rose (1994), reaching the same results. Afterward they set up a panel analysis and achieved opposite results ${ }^{8}$ : airline companies are more inclined to engage in price discrimination strategies in more concentrated markets. This effect becomes stronger for the big city routes subsample ${ }^{9}$.

Focusing on the routes connecting Ireland and UK, Gaggero and Piga (2011) provide the seminal contribution on the effect of market structure on intertemporal pricing dispersion. Consistently with Gerardi and Shapiro (2009), they hold the view that few companies with a relatively large market share can easily price discriminate. However, airlines reduce price discrimination during Christmas and Easter due to the greater homogeneity of travelers.

\footnotetext{
${ }^{6}$ As ticket restrictions Stavins employs the Saturday-night stayover requirement and the advancepurchase requirement. The latter is essentially the same as intertemporal price discrimination.

${ }^{7}$ Besides the ticket restrictions used by Stavins (2001), Giaume and Guillou (2004) take into account some exogenous segmentations such as families, age groups, student status, and events.

${ }^{8}$ Gerardi and Shapiro (2009) explain that the panel approach allows them to estimate the effect of competition by accounting for changes in the competitive structure of a given route over time rather than changes in competitive structures across routes.

${ }^{9}$ The impact of concentration on the 90th percentiles of the fare distribution of the big city routes is twice the impact on the 10th percentile. When there is a large number of business travellers on a route, the increase of concentration has a big impact on the top of the distribution. Conversely, for the leisure route the impact on the 90th and 10th percentiles is almost the same.
} 
In contrast to aforementioned contributions, Hayes and Ross (1998) find no evidence of an empirical relation between price discrimination and market structure in the US airline industry: price dispersion is due primarily to peak load pricing schemes and it is influenced by the characteristics of the carriers operating on a given route. Also, Mantin and Koo (2009) highlight that price dispersion is not affected by the market structure. Instead, the presence of LCCs among the competitors enhances dispersion by inducing FSCs to adopt a more aggressive pricing behaviour ${ }^{10}$.

\section{Data collection}

Data on posted fares were collected to replicate real travellers' behaviour when making reservations. First, we identified plausible round trips, then we retrieve data by simulating reservations using airlines' websites ${ }^{11}$. We observed fares daily starting, generally, sixty booking days before the departure: we define a dataset comprising 19,609 observations on 427 round-trips from November 2006 to February 2011. Our sample includes 10 city-pairs (see Table 1) and 11 airline companies.

\footnotetext{
${ }^{10}$ Alderighi et al (2004) find that when a LCC enters a given route, the FSC incumbent reacts by lowering both leisure and business fares. Further, Fageda et al. (2011) note that traditional carriers are progressively adopting the management practices of LCCs; in particular FSCs, through their low-cost subsidiaries, are able to price more aggressively and hence successfully compete with LCCs.

${ }^{11}$ We avoid any potential distortion on pricing strategies caused by online travel agencies that could propose discounted fares.
} 
Table 1: City-Pairs.

\begin{tabular}{cc}
\hline Origin & Destination \\
\hline \hline Bari & Milan \\
Bari & Rome \\
Brindisi & Milan \\
Brindisi & Rome \\
Catania & Milan \\
Catania & Rome \\
Naples & Milan \\
Naples & Rome \\
Palermo & Milan \\
Palermo & Rome \\
\hline
\end{tabular}

Both FSCs and LCCs are considered (see Table 2); thus we chose the basic services (no add-ons) to make carriers' supply effectively comparable.

Table 2: Airline companies.

\begin{tabular}{llll}
\hline Full Service Carriers & \multicolumn{3}{c}{ Low Cost Carriers } \\
\hline \hline AirOne & Alpieagles & Meridiana & Volare Web \\
Alitalia & Blu Express & MyAir & WindJet \\
Lufthansa & EasyJet & Ryanair & \\
\hline
\end{tabular}

The employment of round-trip helps to accurately define the market structure as we can precisely identify carriers' supply (i.e. if it is a feasible alternative for the traveller and thus if the carrier is a competitor). In addition, round-trips enable us to account precisely for peak-periods and to verify if airlines adjust the pricing behaviour during phases of greater travel demand. Further, FSCs usually post roundtrip fares lower than the sum of two one-way fares. This policy is not adopted by LCCs, hence working with one-way fares will improperly lead to a more expensive supply of FSCs compared to LCCs. By including only round-trip fares we do not encouter this problem ${ }^{12}$.

Airport data were collected to define the daily number of flights of each company and the data about demand. Data on the distance between the two route endpoints are from the World Airport Codes web site, http://www.world-airport-codes.com.

\footnotetext{
${ }^{12}$ The method of Borenstein (1989) and Borenstein and Rose (1994) is largely adopted to halve round trip fares of FSCs.
} 


\section{Empirical strategy}

We specify our empirical strategy by defining two models. The baseline model estimates the effect of market structure and IPD on fares. The extended model estimates the effect of the interaction between IPD and market structure on fares, to test whether airlines are more likely to engage in IPD if competition increases or decreases ${ }^{13}$.

The baseline model is:

$$
\begin{aligned}
\ln \left(P_{j t}\right)= & \beta_{0}+\beta_{1} \text { MarketStructure }_{j}+\beta_{2} \text { BookingDayt }_{t} \\
& +\theta_{3} \text { FlightCharacteristics }_{j}+\theta_{4} \text { ControlDummies }_{j t} \\
& +\varepsilon_{j t}
\end{aligned}
$$

The extended model is:

$$
\begin{aligned}
\ln \left(P_{j t}\right)= & \beta_{0}+\beta_{1} \text { MarketStructure }_{j}+\beta_{2} \text { BookingDayt }_{t} \\
& \left.+\beta_{3} \text { (MarketStructure }_{j} * \text { BookingDay }_{t}\right) \\
& +\theta_{4} \text { FlightCharacteristics }_{j}+\theta_{5} \text { ControlDummies }_{j t} \\
& +\varepsilon_{j t}
\end{aligned}
$$

where $j$ indexes the flight and $t$ the time. Each flight $j$ is defined by the route, the carrier and the date of departure and return; the temporal dimension is represented by the time interval in which we observe fares, thus it goes from 1 to 60 . For some round-trips we have less than sixty observed fares; thus we manage an unbalanced panel.

The dependent variable is the log of the fares. The variable Booking Day measures the IPD and ranges from 1 to 60 . We introduce Booking Day ${ }^{2}$ to account for the

\footnotetext{
${ }^{13}$ The idea of measuring the net effect of price discrimination from varying the market structure is inspired by the approach of Stavins (2001).
} 
non-linearity of Booking Day and, thus, capture the correct size of its impact.

We uptake two proxies of market structure computed at city-pair level ${ }^{14}$ :

- Market Share, the average share of the daily flights operated by an airline at the two endpoints of a city-pair;

- Herfindahl-Hirschman Index (HHI), based on Market Share;

Flight Characteristics includes the following variables:

- Holiday is a peak-period dummy equal to 1 in the cases of summer holidays, winter holidays, bank holidays and public holidays, 0 otherwise.

- $L C C$ is a carrier-related dummy equal to 1 if an airline is a low cost, 0 otherwise.

Control dummies is a set of dummy variables that contains:

- Route: controls for the route-specific effects;

- Year: accounts for annual shocks;

- Month: captures the seasonal effects;

- Departure Time and Return Time are two sets of dummies capturing the effects due to the takeoff time of the flight. These variables are identified by four categorical dummies: Morning (6:00-10:00), Midday (10:00-14:00), Afternoon (14:00-18:00) and Evening (18:00-24:00) ${ }^{15}$;

- Stay: controls for the effects of the length of stay (i.e. how many days elapse between departure and return);

\footnotetext{
${ }^{14}$ We do not compute market structure variables at route level because, working in a peripheral area, almost all the carriers could operate as a monopolist on a given route. Therefore we need the city-pair level to capture the real competition between carriers.

${ }^{15}$ Based on Gaggero and Piga (2011).
} 
$\varepsilon_{j t}$ is the error term.

Given that observations from different time periods are not independent, robust standard errors are clustered by flights.

We treat market structure as exogenous. Basically, we agree with Stavins (2001) claiming that market structure is exogenous in airfare estimations because elements such as "entry barriers prevent new carriers from entering city-pair routes (e.g., limited gate access, incumbent airlines' hub-and-spoke systems, and scale economies in network size). Computerized reservation systems, frequent flier programs, and travel agents' promotion systems raise switching costs and create further scale economies. All of these factors create high costs of entry into the airline industry. In the short run, then, concentration in any given city-pair market can be assumed to be fixed" 16 . The assumption of exogeneity of market structure is tested as explained in the next section.

The market structure does not change in the time we observe fares, so we need to estimate model (1) and model (2) by employing the Random Effects (RE) estimator. The robust Hausman test using the method of Wooldridge (2002) is performed after each regressions to verify the consistency of RE estimates.

In Table 3 we provide descriptive statistics. In our sample there are both monopolistic and more competive markets.

Table 3: Descriptive statistics.

\begin{tabular}{lccccc}
\hline Variables & Obs & Mean & St. Dev. & Min & Max \\
\hline \hline Fares & 19609 & 154.09 & 87.56 & 11.92 & 2069.31 \\
Market Share & 19609 & 0.405 & 0.286 & 0.065 & 1 \\
HHI & 19609 & 0.498 & 0.203 & 0.225 & 1 \\
Booking Day & 19609 & 24.669 & 14.890 & 1 & 60 \\
Holiday & 19609 & 0.458 & 0.498 & 0 & 1 \\
LCC & 19609 & 0.455 & 0.498 & 0 & 1 \\
\hline
\end{tabular}

\footnotetext{
${ }^{16}$ Stavins follows the approach of Graham et al. (1983). (These arguments are also provided in the previous Working Papers 96-7, Federal Reserve Bank at pg. 25).
} 


\section{Robustness check}

In previous section we distinguish carriers of two types, FSCs and LCCs, assuming similar operating characteristics and pricing behaviour within types. Using this distinction, we employ some carrier-related dummy variables subjected to economic interpretation. As a robustness check, we verify whether the results change when carrier-specific dummies are introduced in place of carrier-related dummies.

Moreover, we test the exogeneity of market structure variables. Actually, Borenstein (1989) asserts that market structure could be a function of the fares charged, thus correlated with the error term. Failing the assumptions of the RE model, coefficient estimates could be biased. Therefore, we employ the GMM estimator as a further robustness check to demonstrate the exogeneity of Market Share and HHI and, therefore, the unbiasedness of the GLS RE estimates. We do use the instruments designed by Borenstein (1989), largely adopted in the related literature ${ }^{17}$. The first two are targeted to the Market Share and the HHI, respectively. GENP is the observed carrier's geometric mean of enplanements at the endpoints divided by the sum across all carriers of the geometric mean of each carrier's enplanements at the endpoint airports:

$$
G E N P=\frac{\sqrt{E N P_{i, 1} * E N P_{i, 2}}}{\sum \sqrt{E N P_{j, 1} * E N P_{j, 2}}}
$$

where $i$ is the observed airline and $j$ refers to all airlines. To the HHI, QHHI is the square of the market share fitted value plus the rescaled sum of the squares of all other carriers' shares. In formula:

$$
Q H H I=\widehat{M S}+\frac{H H I-M S^{2}}{(1-M S)^{2}}(1-\widehat{M S})^{2}
$$

where MS stands for the Market Share and $\widehat{M S}$ is the fitted value of MS from the first stage regression. Further $\log$ (Distance) is the logarithm of the distance in kilometres between the two route endpoints. To be more clear, we employ GENP

\footnotetext{
${ }^{17}$ For a fuller description of the instruments see Borenstein (1989) pg 351-353.
} 
and $\log$ (Distance) to estimate the models with Market Share as the market structure variable; we use $Q H H I$ and $\log$ (Distance) to estimate the models with $H H I$ as the market structure variable.

In the extended model (2) we add the interaction between Booking Day and market structure variables. The interaction could be endogenous too, so we include, as additional instrument, the interaction between Booking Day and GENP or QHHI, respectively.

\section{Results}

Before proceeding with discussing empirical results, it is worth to look at Figure 1 showing the relationship between posted fares and days missing to departure.

Figure 1: Intertemporal fares profile.

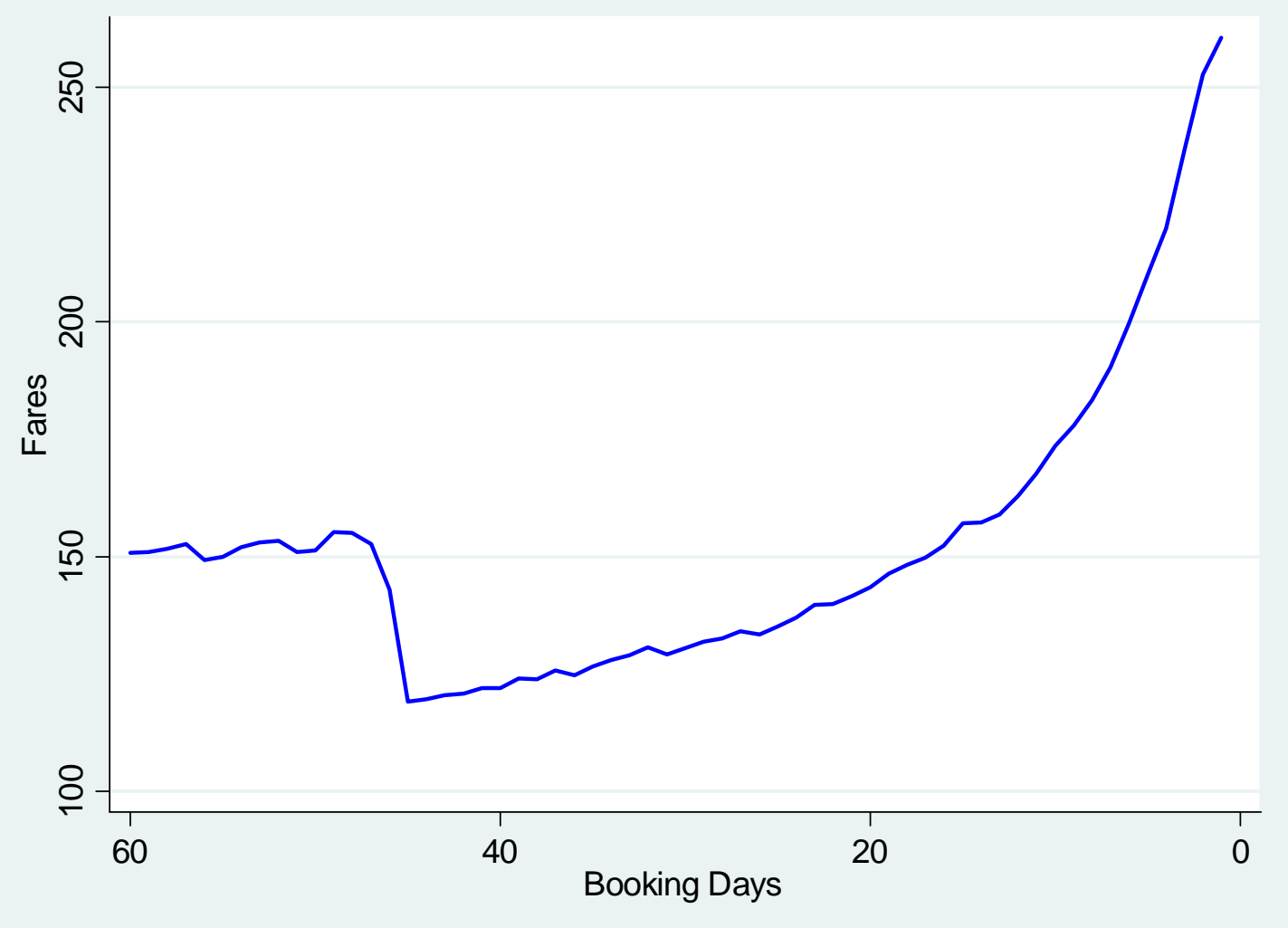


Consistently with some aforementioned empirical works, it emerges a non-monotonic relationship between average posted fares and days missing to departure. Airlines set the initial level of fares, subject to slight changes for, roughly, fifteen days; then, fares sharply decrease until reaching the minimum level. Henceforth, airlines increase fares up to the departure day; such an increment becomes greater in the last fifteen days. We delve into the discussion of this point when presenting regressions' results.

Figure 2 shows the density distribution of fares: the mass of values is concentrated between 50 and 200 euros.

Figure 2: Density distribution of fares.

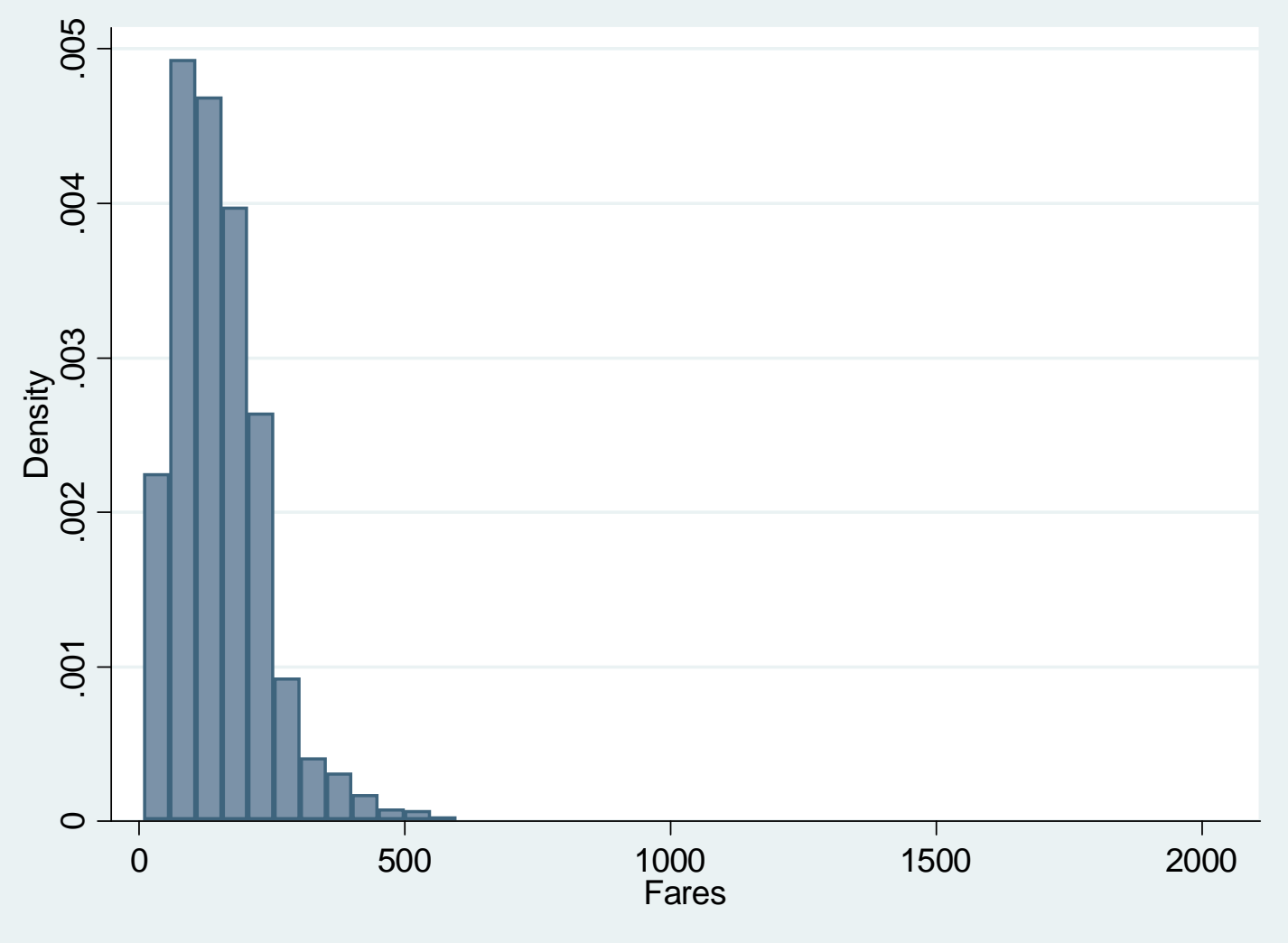

Table 4 displays the results of the Baseline Model. As expected, Market Share and $H H I$ have a positive and highly significant impact on fares: the market power due to the higher market concentration allows airlines to increase fares. Specifically, 
holding other variables constant, $10 \%$ increase in Market Share implies an average fare increase of $6.4 \%$ and $10 \%$ increase of $\mathrm{HHI}$ entails an average fare increase of $5.7 \%$.

Table 4: Baseline Model.

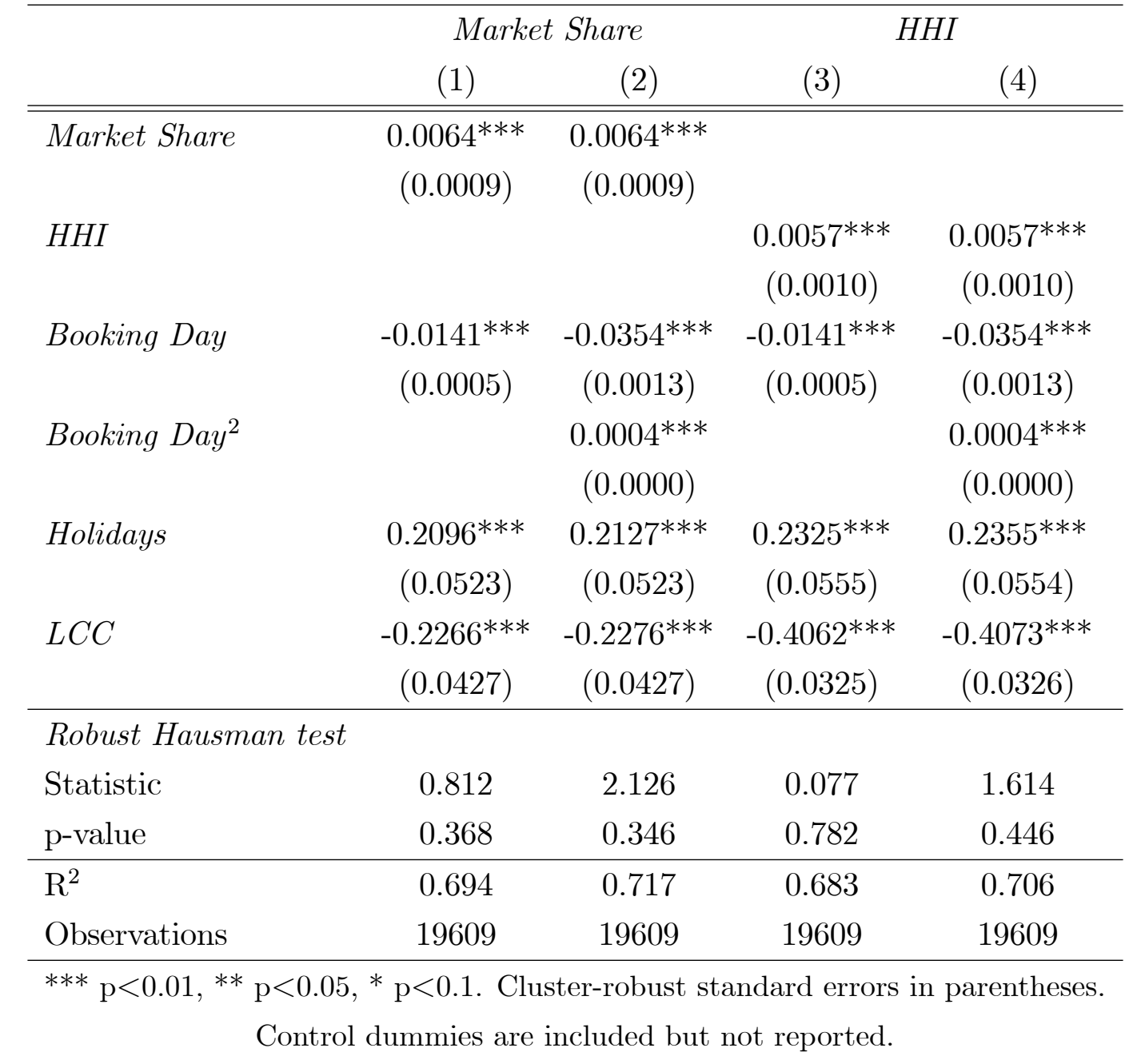

Each model is first estimated with only the variable Booking Day; afterward we add Booking Day² to check the non-linearity. Booking Day is negative and significant, meaning that airlines do engage in IPD strategies. When Booking Day ${ }^{2}$ is introduced, a non monotonic trend, J-shaped, appears. Booking Day ${ }^{2}$ is positive and highly significant: very early-bookers pay moderately higher fares compared to 
middle-bookers, whereas late-bookers pay the highest fares. On a technical level, the square allows us to correctly identify the shape of Booking Day and seize its full impact, since its coefficient has more than doubled. Moreover, the performance of the model improves in regressions with Booking Day since the $\mathrm{R}^{2}$ is comparatively higher. Nevertheless, coefficients of Booking Day ${ }^{2}$ are very small: during periods long before the departure, purchasing the ticket one day earlier means that the traveler pays on average only $0.04 \%$ more. Moreover, we estimate that, in our sample, the minimum of the J-curve is reached relatively early, between the forty-third and the forty-fourth day before departure. Considered together these two results show that the hook of the $\mathrm{J}$ (i.e. the decreasing part of the fare distribution) is short and flattened: very early bookers do not pay much higher fares. After the minimum fare is posted, then buying the ticket the day later would mean that the traveler would pay on average $3.54 \%$ more. Not considering Booking Day ${ }^{2}$ in the model leads to an underestimation of the marginal effect of Booking Day ${ }^{2}$ : fares posted the day after appear to be higher by only $1.41 \%$.

The J-shaped intertemporal profile of fares has various interpretations. One of these is the intuition of Gaggero (2010) suggesting that it reflects a pattern opposite to that of travellers' demand elasticity. On the other hand, a common wisdom among travellers is "the later you buy, the more you pay the ticket", thus price sensitive consumers tend to buy in advance. Being aware of this, airlines exploit consumers' bounded rationality and, thus, extract their surplus by posting moderatly higher fares for very-early purchasers that will buy tickets believing to pay the cheapest fares. Finally, the non monotonicity can also be explained considering that airlines set fares before demand is realized on the basis of past experience on a given route. Henceforth, they verify how many seats are sold at that prices and are able to modulate fares to the actual demand, thanks to the easiness with which online fares can be changed. A fare drop is an indication that the actual demand is not as expected, therefore it responds to the need of raising the load factor ${ }^{18}$.

\footnotetext{
${ }^{18}$ Bilotkach et (2012) provide evidence that the presence of drops in offered fares over time is an indicator of an active yield management intervention.
} 
The results of the control variables are those expected. Holiday is positive and significant: during peak-periods airlines exploit the greater demand of travel and set fares on average 21 to $24 \%$ higher than during off-peak periods. $L C C$ is negative and significant, underlining the fact that LCCs price lower than $\mathrm{FSCs}^{19}$. In models with Market Share as predictor, LCCs appear to price 23\% lower than FSCs, whereas in models with $H H I$ as predictor, LCCs appear to price $41 \%$ lower than FSCs. The different impact may be due to the explanatory power of Market Share, which captures the straight effect of market power on fares, and therefore softens the impact of LCCs.

In the ensuing discussion of the results, we focus on the new variables added to the model, since the impact of the variables already in the baseline model is the same or, at most, the magnitude slightly decreases due to the introduction of a greater number of variables.

Table 5 shows the results of the Extended Model I. Booking Day is still negative and significant, while its interaction with Market Share or HHI is positive and significant.

\footnotetext{
${ }^{19}$ In line with the findings of Bergantino (2009). Exploring carriers' pricing behavior on some Italian routes involving small airports, she highlights, in fact, that, on average, LCCs post fares half those of FSCs.
} 
Table 5: Extended Model I.

\begin{tabular}{|c|c|c|c|c|}
\hline & \multicolumn{2}{|c|}{ Market Share } & \multicolumn{2}{|c|}{$H H I$} \\
\hline & $(1)$ & $(2)$ & (3) & $(4)$ \\
\hline Market Share & $\begin{array}{c}0.0049^{* * *} \\
(0.0010)\end{array}$ & $\begin{array}{c}0.0051^{* * *} \\
(0.0010)\end{array}$ & & \\
\hline$H H I$ & & & $\begin{array}{c}0.0042^{* * *} \\
(0.0011)\end{array}$ & $\begin{array}{c}0.0047^{* * *} \\
(0.0011)\end{array}$ \\
\hline Booking Day & $\begin{array}{c}-0.0167^{* * *} \\
(0.0008)\end{array}$ & $\begin{array}{c}-0.0375^{* * *} \\
(0.0015)\end{array}$ & $\begin{array}{c}-0.0172^{* * *} \\
(0.0013)\end{array}$ & $\begin{array}{c}-0.0375^{* * *} \\
(0.0016)\end{array}$ \\
\hline Booking Day ${ }^{2}$ & & $\begin{array}{c}0.0004^{* * *} \\
(0.0000)\end{array}$ & & $\begin{array}{c}0.0004^{* * *} \\
(0.0000)\end{array}$ \\
\hline Market Share*Booking Day & $\begin{array}{c}0.0001^{* * *} \\
(0.0000)\end{array}$ & $\begin{array}{c}0.0001^{* * *} \\
(0.0000)\end{array}$ & & \\
\hline HHI*Booking Day & & & $\begin{array}{c}0.0001^{* * *} \\
(0.0000)\end{array}$ & $\begin{array}{c}0.0000^{* * *} \\
(0.0000)\end{array}$ \\
\hline Holidays & $\begin{array}{c}0.2103^{* * *} \\
(0.0522)\end{array}$ & $\begin{array}{c}0.2132^{* * *} \\
(0.0523)\end{array}$ & $\begin{array}{c}0.2336^{* * *} \\
(0.0554)\end{array}$ & $\begin{array}{c}0.2363^{* * *} \\
(0.0554)\end{array}$ \\
\hline$L C C$ & $\begin{array}{c}-0.2280^{* * *} \\
(0.0424)\end{array}$ & $\begin{array}{c}-0.2288^{* * *} \\
(0.0425)\end{array}$ & $\begin{array}{c}-0.4064^{* * *} \\
(0.0325)\end{array}$ & $\begin{array}{c}-0.4074^{* * *} \\
(0.0325)\end{array}$ \\
\hline Robust Hausman test & & & & \\
\hline $\begin{array}{l}\text { Statistic } \\
\text { p-value }\end{array}$ & $\begin{array}{l}0.916 \\
0.632\end{array}$ & $\begin{array}{l}2.318 \\
0.509\end{array}$ & $\begin{array}{l}0.107 \\
0.948\end{array}$ & $\begin{array}{l}1.679 \\
0.642\end{array}$ \\
\hline $\mathrm{R}^{2}$ & 0.696 & 0.719 & 0.683 & 0.707 \\
\hline Observations & 19609 & 19609 & 19609 & 19609 \\
\hline
\end{tabular}

${ }^{* * *} \mathrm{p}<0.01,{ }^{* *} \mathrm{p}<0.05,{ }^{*} \mathrm{p}<0.1$. Cluster-robust standard errors in parentheses. Control dummies are included but not reported.

The negative impact of Booking Day is reduced by $0.1 \%$ when market concentration increases by $10 \%$. Our findings provide arguments in favour of competitive discrimination like Borestein and Rose (1994), Stavins (2001) and Giaume and Guillou (2004), although contrasting with Gerardi and Shapiro (2007) and Gaggero and 
Piga (2011): competition does not prevent airlines from using IPD strategies.

Table 6 illustrates the results of the Extended Model II by which we investigate IPD further. We verify whether airlines adjust their behaviour during phases characterized by a higher demand of travel. To this end we employ the interaction between Booking Day and Holiday, which has a positive and significant impact on fares. 
Table 6: Extended Model II.

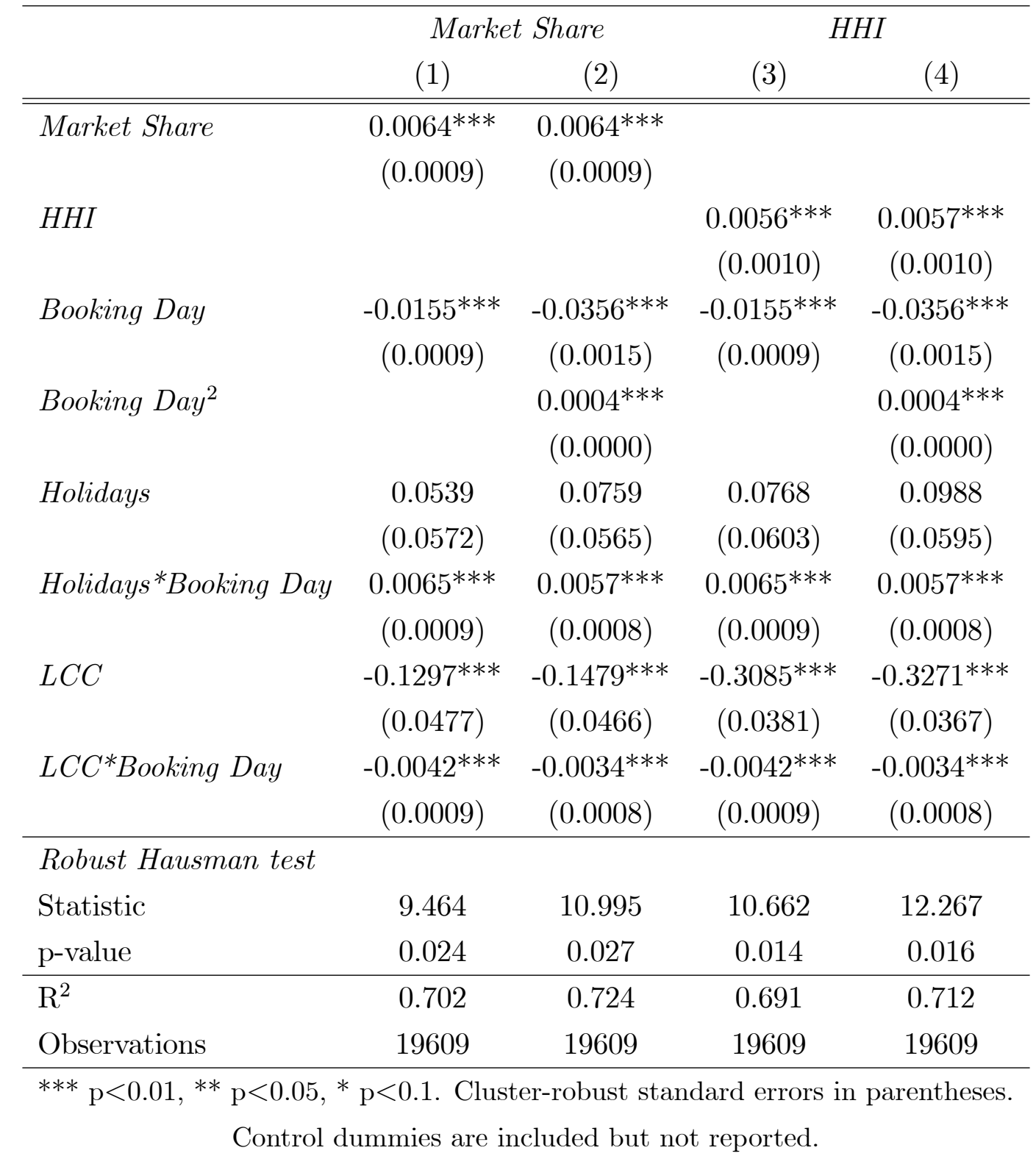

The effect of Booking Day on fares posted for peak periods is 0.57 to 0.65 percentage points less than for off-peak periods. This finding is due basically to two facts. The greater demand allows airlines to decrease discrimination because they can fill the plane even without offering discounted fares. Moreover, during holidays travellers 
are more homogeneous, as people journey mainly for tourism; thus discrimination, being based on the heterogeneity of travellers, becomes less effective. The variable Holiday becomes insignificant and the coefficients decrease across regressions: likely its impact is captured by the interaction with Booking Day and the other interaction added to the model.

Furthermore, we focus on IPD strategies implemented by LCCs. To this end we employ the interaction between the Booking Day and $L C C$, which has a negative impact on fares. The effect of Booking Day on fares posted by LCCs is 0.34 to 0.42 percentage points higher than with FSCs. This result underlines that LCCs engage in stronger IPD, coherent with the more aggressive pricing behavior of LCCs.

In the bottom of Table 4 to 6 we report the results of the Robust Hausman test that lead not to reject the null hypothesis that RE provide consistent estimates. In Table 7 to 8 (in Appendix) we provide the results of the first robustness check, in which we control for carrier-specific effects. Estimates do not change when we make more specific hypotheses about the behavior of each carrier. From Table 9 to 11 (in Appendix) we show GMM estimates ${ }^{20}$. In the bottom of each table, we report the results of tests performed. The first test concerns the power of the instruments: for all the models, the Kleibergen-Paap rk Statistic, the robust analog of the Cragg-Donald Statistic, is far greater than the critical values ${ }^{21}$, allowing us therefore strongly to reject the null of weakness of the instruments. Second, the results of the Hansen J test, which checks the validity of the instruments, fail to reject the null hypothesis: the overidentifying restriction is valid for each of the regressions run. Finally, the results of test $\mathrm{C}$, concerning the exogeneity of the market structure variables, fail to reject the null hypothesis of exogeneity of both Market Share and HHI for all the specifications. This means that the basic hypothesis of the RE model, i.e. no correlation between the regressors and the error term, is satisfied, so estimates are consistent. Moreover, the GMM estimates are even close to the RE GLS estimates,

\footnotetext{
${ }^{20}$ Current data on number of passengers do not cover the whole sample of round trip fares, so estimations are carried out on a smaller sample.

${ }^{21}$ Critical values were computed by Stock and Yogo (2005) for the Cragg-Donald Statistic. Results need to be interpreted with caution only if the Kleibergen-Paap rk Statistic is close to the critical values. However, this is not our case.
} 
which underlines the robustness of the results.

\section{Summary and conclusions}

This paper aimed at studing airline pricing behaviour dealing with two basic issues. The first is to measure the extent to which intramodal competition, captured by market structure indexes, influences fares charged to travellers. The second is to shed light on the intertemporal profile of fares to verify if airlines undertake intertemporal price discrimination (IPD) strategies and whether IPD is of monopolistic-type or competitive-type. Using a unique dataset, we studied airline pricing behaviour removing the influence of intermodal competition; to this aim, we focused on the southern Italian market that exhibits a limited intermodal competition, thus airline pricing strategies are the straight results of air-related competition.

Our main findings claim that airlines exploit their dominant position on a citypair: when the intramodal competition reduces, airlines apply higher fares since they exploit the greater market power arising from more concentrated maket structure. Moreover, we find evidence that airlines do undertake IPD strategies: the intertemporal profile of fares appears to follow a J-curve. The empirical evidence is in favor of "competitive-type discrimination": a more competitive market structure fosters the implementation of IPD strategies. Further, airline pricing strategies differ depending on whether the carrier is a low cost or a traditional carrier. Actually, LCCs appear to adopt a more aggressive pricing behavior: on average they set lower fares and undertake stronger IPD strategies.

One might argue that price discrimination is only beneficial for airlines. Nevertheless, in more competitive markets airlines charge lower fares that, together with the IPD, allow them to target larger segments of demand, which leads to a "democratisation" of air travel.

Developments for future research could be an enlargement of the territorial coverage in order to compare different exogenously determined accessibility conditions and, thus, to measure the impact of modal and intermodal competition on accessibil-

ity. Furthermore, we aim to take into account the local government subsidies often 
granted to airlines, to evaluate their impact on fares and pricing strategies and, thus, on the net welfare of the area in question. 


\section{References}

[1] Abrate, G., Fraquelli, G., Viglia, G. (2010). Dynamic pricing strategies and customer heterogeneity: the case of European hotels. HERMES Working Paper, $10-7$.

[2] Alderighi, M., Cento, A., Nijkamp, P., Rietveld, P. (2004). The Entry of LowCost Airlines: Price Competition in the European Airline Market. Tinbergen Institute Discussion Paper, 04-074/3.

[3] Alderighi, M., Piga, C.A. (2010). On-line Booking and Revenue Management: Evidence from a Low-Cost Airline. Review of Economic Analysis, 2(3): 272-286.

[4] Alves, C.F., Barbot, C. (2009). Price Discrimination Strategies of Low-Cost Carriers. Journal of Transport Economics and Policy, 43(3): 345-363.

[5] Bachis, E., Piga, C.A. (2007a). Hub Premium, Airport Dominance and Market Power in the European Airline Industry. Discussion Paper Series 2007_11, Department of Economics, Loughborough University.

[6] Bachis, E., Piga, C.A. (2007b). Pricing strategies by European traditional and low cost airlines. Or, when is it the best time to book on line?. in Darin Lee (ed.), Advances in Airline Economics, Volume 2: The Economics of Airline Institutions, Operations and Marketing, Elsevier: Amsterdam, ch. 10, 319-344.

[7] Belobaba, P. P. (1987). Air travel demand and airline seat inventory management. Flight Transportation Laboratory Report R87-7. Cambridge, MA: The Massachusetts Institute of Technology.

[8] Bilotkach, V., Gaggero, A.A., Piga, C.A. (2012). Airline Pricing under Different Market Conditions: Evidence from European Low-Cost Carriers. Discussion Paper Series 2012_01, Department of Economics, Loughborough University.

[9] Bergantino, A.S. (2009). Le strategie di prezzo delle compagnie tradizionali e delle low cost. Implicazioni per i sistemi aeroportuali minori: il caso della Puglia. 
Trasporti, ambiente e territorio. La ricerca di un nuovo equilibrio, Franco Angeli, Milano, 77-91.

[10] Borenstein, S. (1985). Price Discrimination in Free-Entry Markets. The RAND Journal of Economics, 16(3) 380-397.

[11] Borenstein, S. (1989). Hubs and High Fares: Dominance and Market Power in the U.S. Airline Industry. The RAND Journal of Economics, 20(3): 344-365.

[12] Borenstein, S., Rose, N.L. (1994). Competition and price dispersion in the US airline industry. The Journal of Political Economy, 102(4): 653-683.

[13] Carlsson, F. (2004). Prices and Departures in European Domestic Aviation Markets. Review of Industrial Organization: 24(1): 37-49.

[14] Dana, J.D. (1998). Advance-Purchase Discounts and Price Discrimination in Competitive Markets. The Journal of Political Economy, 106(2): 395-422.

[15] Dana, J.D. (1999). Equilibrium Price Dispersion Under Demand Uncertainty: The Roles of Costly Capacity and Market Structure. Rand Journal of Economics, 30 (4): 632-660.

[16] Evans, W.N., Kessides, J.N. (1993). Localised Market Power in the U.S. Airline Industry. Review of Economics \& Statistics, 75(1): 66-75.

[17] Fageda, X., Jiménez, J.L., Perdiguero, J. (2011). Price rivalry in airline markets: a study of a successful strategy of a network carrier against a low-cost carrier. Journal of Transport Geography, 19(4): 658-669.

[18] Gaggero, A.A. (2010). Airline Pricing and Competition: the J-curve of airline fares. LAP Lambert Academic Publishing.

[19] Gaggero, A.A., Piga, C.A. (2010). Airline competition in the British Isles. Transportation Research Part E, 46(2): 270-279. 
[20] Gaggero, A.A., Piga, C.A. (2011). Airline Market Power and Intertemporal Price Dispersion. Journal of Industrial Economics, 59(4): 552-577.

[21] Gale, I.L. (1993). Price Dispersion in a Market with Advance-Purchases. Review of Industrial Organization, 8(4): 451-464.

[22] Gale, I.L., Holmes, T.J. (1992). The efficiency of advance-purchase discounts in the presence of aggregate demand uncertainty. International Journal of Industrial Organization, 10(3): 413-437.

[23] Gale, I.L., Holmes, T.J. (1993). Advance-Purchase Discounts and Monopoly Allocation of Capacity. American Economic Review, 83(1): 135-46.

[24] Gerardi, K., Shapiro A. (2009). Does Competition Reduce Price Dispersion? New Evidence From the Airline Industry. Journal of Political Economy, 117(1): $1-37$.

[25] Giaume, S., Guillou, S. (2004). Price discrimination and concentration in European airline markets. Journal of Air Transport Management, 10(5): 305-310.

[26] Graham, D. R., Kaplan D. P., Sibley D. S. (1983). Efficiency and Competition in the Airline Industry. Bell Journal of Economics, 14(1): 118-138.

[27] Hayes, K., Ross, L. (1998). Is Airline Price Dispersion the Result of Careful Planning or Competitive Forces? Review of Industrial Organization, 13(5): 523542.

[28] Holmes, T. (1989). The Effects of Third-Degree Price Discrimination in Oligopoly. American Economic Review, 79(1): 244-250.

[29] Lofgren, K.G. (1971). The theory of intertemporal price discrimination. An outline. Swedish Journal of Economics, 73(3): 333-343.

[30] Mantin, B., Koo, B. (2009). Dynamic price dispersion in airline market. Transportation Research Part E, 45(6): 1020-1029. 
[31] Stavins, J. (2001). Price Discrimination in the Airline Market: The Effect of Market Concentration. The Review of Economics and Statistics, 83(1): 200-202.

[32] Stock, J.H., Yogo, M. (2005). Testing for Weak Instruments in IV Regression. Identification and Inference for Econometric Models: A Festschrift in Honor of Thomas Rothenberg, Donald W.K.A., Stock, J.H. eds. Cambridge University Press, 80-108.

[33] Stokey, N. (1979). Intertemporal price discrimination. Quarterly Journal of Economics 93(3): 355-371.

[34] Tirole, J. (1988). The Theory of Industrial Organization. Cambridge, MA: The MIT Press.

[35] Wooldridge, J. M. (2002). Econometric Analysis of Cross Section and Panel Data. Cambridge, MA: The MIT Press. 


\section{Appendix}

Table 8: Baseline Model with carrier-specific dummies.

\begin{tabular}{lcccc}
\hline \multicolumn{4}{c}{ Market Share } & \multicolumn{2}{c}{$H H I$} \\
& $(1)$ & $(2)$ & $(3)$ & $(4)$ \\
\hline \hline Market Share & $0.0060^{* * *}$ & $0.0060^{* * *}$ & & \\
HHI & $(0.0012)$ & $(0.0012)$ & & \\
& & & $0.0050^{* * *}$ & $0.0050^{* * *}$ \\
Booking Day & & & $(0.0009)$ & $(0.0009)$ \\
& $-0.0141^{* * *}$ & $-0.0354^{* * *}$ & $-0.0141^{* * *}$ & $-0.0354^{* * *}$ \\
Booking Day ${ }^{*}$ & $(0.0005)$ & $(0.0013)$ & $(0.0005)$ & $(0.0013)$ \\
& & $0.0004^{* * *}$ & & $0.0004^{* * *}$ \\
Holidays & & $(0.0000)$ & & $(0.0000)$ \\
& $0.2410^{* * *}$ & $0.2442^{* * *}$ & $0.2440^{* * *}$ & $0.2471^{* * *}$ \\
\hline Robust Hausman test & $(0.0447)$ & $(0.0447)$ & $(0.0451)$ & $(0.0450)$ \\
Statistic & & & & \\
p-value & 0.011 & 1.224 & 0.039 & 1.124 \\
\hline R ${ }^{2}$ & 0.917 & 0.542 & 0.844 & 0.570 \\
Observations & 0.729 & 0.754 & 0.729 & 0.753 \\
\hline$* * *$ p & 19609 & 19609 & 19609 & 19609 \\
\hline
\end{tabular}

$* * * \mathrm{p}<0.01,{ }^{* *} \mathrm{p}<0.05,{ }^{*} \mathrm{p}<0.1$. Cluster-robust standard errors in parentheses. Control dummies are included but not reported. 
Table 9: Extended Model I with carrier-specific dummies.

\begin{tabular}{|c|c|c|c|c|}
\hline & \multicolumn{2}{|c|}{ Market Share } & \multicolumn{2}{|c|}{$H H I$} \\
\hline & $(1)$ & $(2)$ & $(3)$ & $(4)$ \\
\hline Market Share & $\begin{array}{c}0.0045^{* * *} \\
(0.0013)\end{array}$ & $\begin{array}{c}0.0046^{* * *} \\
(0.0013)\end{array}$ & & \\
\hline$H H I$ & & & $\begin{array}{c}0.0035^{* * *} \\
(0.0010)\end{array}$ & $\begin{array}{c}0.0039 * * * \\
(0.0010)\end{array}$ \\
\hline Booking Day & $\begin{array}{c}-0.0167^{* * *} \\
(0.0008)\end{array}$ & $\begin{array}{c}-0.0375^{* * * *} \\
(0.0015)\end{array}$ & $\begin{array}{c}-0.0172^{* * *} \\
(0.0013)\end{array}$ & $\begin{array}{c}-0.0375^{* * *} \\
(0.0016)\end{array}$ \\
\hline Booking Day ${ }^{2}$ & & $\begin{array}{c}0.0004^{* * *} \\
(0.0000)\end{array}$ & & $\begin{array}{c}0.0004^{* * *} \\
(0.0000)\end{array}$ \\
\hline Market Share*Booking Day & $\begin{array}{c}0.0001^{* * *} \\
(0.0000)\end{array}$ & $\begin{array}{c}0.0001^{* * *} \\
(0.0000)\end{array}$ & & \\
\hline$H H I^{*}$ Booking Day & & & $\begin{array}{c}0.0001^{* * *} \\
(0.0000)\end{array}$ & $\begin{array}{c}0.0000^{* * *} \\
(0.0000)\end{array}$ \\
\hline Holidays & $\begin{array}{c}0.2416^{* * *} \\
(0.0446)\end{array}$ & $\begin{array}{c}0.2447^{* * *} \\
(0.0447)\end{array}$ & $\begin{array}{c}0.2451^{* * *} \\
(0.0450)\end{array}$ & $\begin{array}{c}0.2479 * * * \\
(0.0450)\end{array}$ \\
\hline Robust Hausman test & & & & \\
\hline Statistic & 0.022 & 1.408 & 0.285 & 1.318 \\
\hline p-value & 0.989 & 0.704 & 0.867 & 0.725 \\
\hline $\mathrm{R}^{2}$ & 0.753 & 0.755 & 0.730 & 0.754 \\
\hline Observations & 19609 & 19609 & 19609 & 19609 \\
\hline
\end{tabular}
$* * * \mathrm{p}<0.01,{ }^{* *} \mathrm{p}<0.05, * \mathrm{p}<0.1$. Cluster-robust standard errors in parentheses. Control dummies are included but not reported. 
Table 10: Baseline Model. GMM estimator.

\begin{tabular}{|c|c|c|c|c|}
\hline & \multicolumn{2}{|c|}{ Market Share } & \multicolumn{2}{|c|}{$H H I$} \\
\hline & (1) & $(2)$ & $(3)$ & $(4)$ \\
\hline Market Share & $\begin{array}{l}0.0068^{* * *} \\
(0.0013)\end{array}$ & $\begin{array}{c}0.0069 * * * \\
(0.0013)\end{array}$ & & \\
\hline$H H I$ & & & $\begin{array}{c}0.0079^{* * *} \\
(0.0013)\end{array}$ & $\begin{array}{c}0.0080 * * * \\
(0.0012)\end{array}$ \\
\hline Booking Day & $\begin{array}{c}-0.0136^{* * *} \\
(0.0005)\end{array}$ & $\begin{array}{c}-0.0330 * * * \\
(0.0014)\end{array}$ & $\begin{array}{c}-0.0135^{* * *} \\
(0.0005)\end{array}$ & $\begin{array}{c}-0.0331^{* * *} \\
(0.0014)\end{array}$ \\
\hline Booking Day ${ }^{2}$ & & $\begin{array}{c}0.0004^{* * *} \\
(0.0000)\end{array}$ & & $\begin{array}{c}0.0004^{* * *} \\
(0.0000)\end{array}$ \\
\hline Holidays & $\begin{array}{c}0.1851^{* * *} \\
(0.0597\end{array}$ & $\begin{array}{c}0.1898^{* * *} \\
(0.0599)\end{array}$ & $\begin{array}{c}0.2004^{* * *} \\
(0.0623)\end{array}$ & $\begin{array}{c}0.2055^{* * *} \\
(0.0623)\end{array}$ \\
\hline$L C C$ & $\begin{array}{c}-0.2486^{* * *} \\
(0.0555)\end{array}$ & $\begin{array}{c}-0.2466^{* * *} \\
(0.0555)\end{array}$ & $\begin{array}{c}-0.4285^{* * *} \\
(0.0374)\end{array}$ & $\begin{array}{c}-0.4290^{* * *} \\
(0.0374)\end{array}$ \\
\hline Test of weak-instruments & & & & \\
\hline Kleibergen-Paap rk Statistic & 114.872 & 114.892 & 360.793 & 360.755 \\
\hline $\begin{array}{l}\text { Stock and Yogo critical value } \\
\text { Test of overidentifying restrictions }\end{array}$ & 19.93 & 19.93 & 19.93 & 19.93 \\
\hline Hansen J Statistic & 0.060 & 0.050 & 0.045 & 0.036 \\
\hline Hansen J p-value & 0.807 & 0.823 & 0.833 & 0.850 \\
\hline Test of endogeneity & & & & \\
\hline C Test Statistic & 0.049 & 0.025 & 2.758 & 2.714 \\
\hline $\mathrm{C}$ Test p-value & 0.825 & 0.875 & 0.097 & 0.100 \\
\hline $\mathrm{R}^{2}$ & 0.708 & 0.728 & 0.697 & 0.717 \\
\hline Observations & 16478 & 16478 & 16478 & 16478 \\
\hline
\end{tabular}

${ }^{* * *} \mathrm{p}<0.01,{ }^{* *} \mathrm{p}<0.05,{ }^{*} \mathrm{p}<0.1$. Cluster-robust standard errors in parentheses. Control dummies are included but not reported. 
Table 11: Extended Model I. GMM estimator.

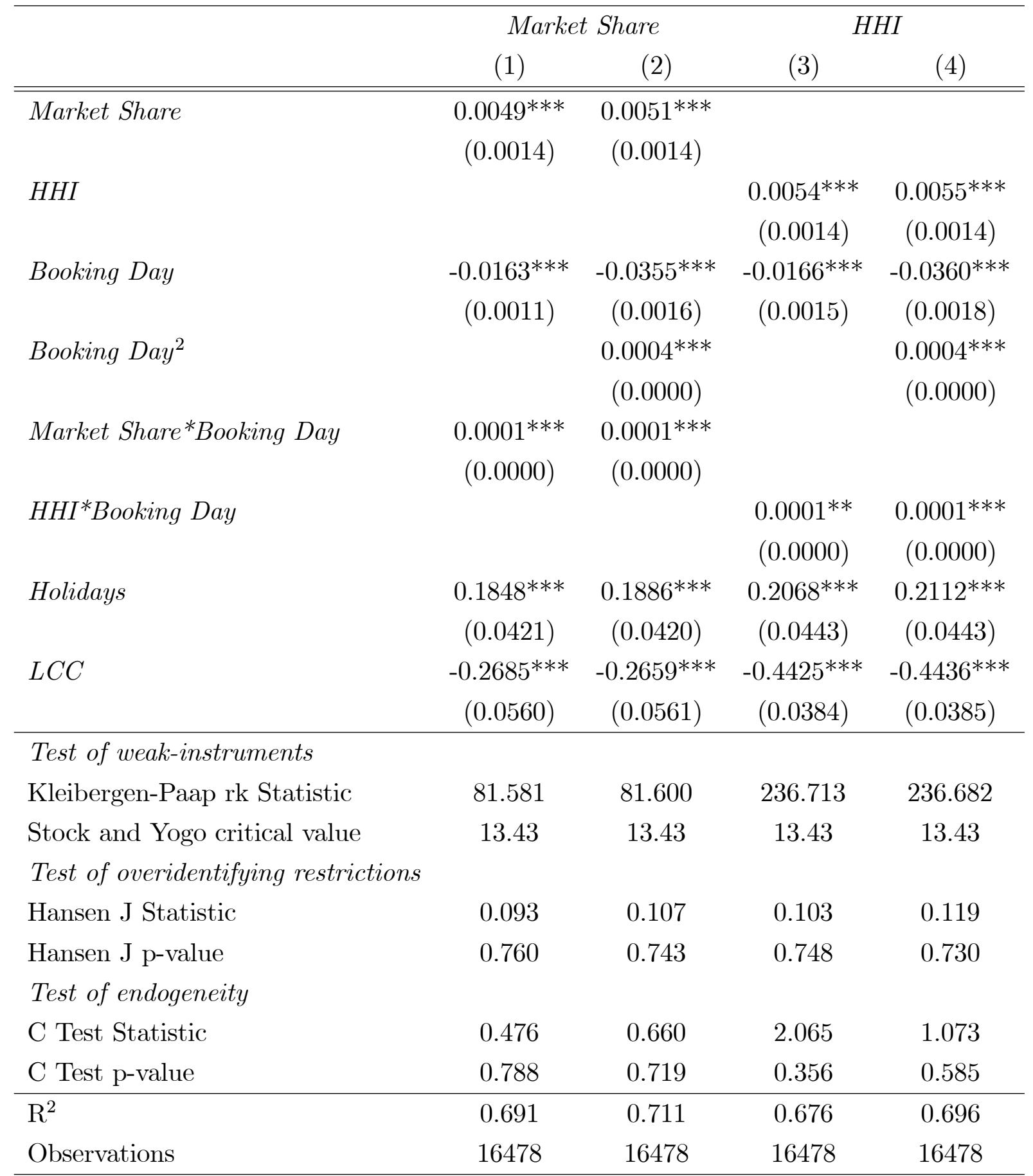

$* * * \mathrm{p}<0.01, * * \mathrm{p}<0.05, * \mathrm{p}<0.1$. Cluster-robust standard errors in parentheses.

Control dummies are included but not reported.

33 
Table 12: Extended Model II. GMM estimator.

\begin{tabular}{|c|c|c|c|c|}
\hline & \multicolumn{2}{|c|}{ Market Share } & \multicolumn{2}{|c|}{$H H I$} \\
\hline & $(1)$ & $(2)$ & (3) & (4) \\
\hline \multirow[t]{2}{*}{ Market Share } & $0.0068^{* * *}$ & $0.0069^{* * *}$ & & \\
\hline & $(0.0013)$ & $(0.0013)$ & & \\
\hline \multirow[t]{2}{*}{$H H I$} & & & $0.0079^{* * *}$ & $0.0080^{* * *}$ \\
\hline & & & $(0.0013)$ & $(0.0013)$ \\
\hline \multirow[t]{2}{*}{ Booking Day } & $-0.0137^{* * *}$ & $-0.0322 * * *$ & $-0.0133^{* * *}$ & $-0.0320^{* * *}$ \\
\hline & $(0.0010)$ & $(0.0015)$ & $(0.0010)$ & $(0.0015)$ \\
\hline \multirow[t]{2}{*}{ Booking Day ${ }^{2}$} & & $0.0003^{* * *}$ & & $0.0003^{* * *}$ \\
\hline & & $(0.0000)$ & & $(0.0000)$ \\
\hline \multirow[t]{2}{*}{ Holidays } & 0.0688 & 0.0853 & 0.0885 & 0.1055 \\
\hline & $(0.0638)$ & $(0.0632)$ & $(0.0665)$ & $(0.0658)$ \\
\hline \multirow[t]{2}{*}{ Holidays*Booking Day } & $0.0046^{* * *}$ & $0.0042^{* * *}$ & $0.0044^{* * *}$ & $0.0039^{* * *}$ \\
\hline & $(0.0010)$ & $(0.0009)$ & $(0.0010)$ & $(0.0009)$ \\
\hline \multirow[t]{2}{*}{$L C C$} & $-0.1143^{* *}$ & $-0.1272^{* *}$ & $-0.2849^{* * *}$ & $-0.3002^{* * *}$ \\
\hline & $(0.0579)$ & $(0.0564)$ & $(0.0408)$ & $(0.0393)$ \\
\hline \multirow[t]{2}{*}{$L C C^{*}$ Booking Day } & $-0.0054^{* * *}$ & $-0.0048^{* * *}$ & $-0.0058^{* * *}$ & $-0.0052^{* * *}$ \\
\hline & $(0.0009)$ & $(0.0009)$ & $(0.0009)$ & $(0.0009)$ \\
\hline \multicolumn{5}{|l|}{ Test of weak-instruments } \\
\hline Kleibergen-Paap rk Statistic & 115.135 & 115.148 & 361.867 & 361.841 \\
\hline \multirow{2}{*}{\multicolumn{5}{|c|}{$\begin{array}{l}\text { Stock and Yogo critical value } \\
\text { Test of overidentifying restrictions }\end{array}$}} \\
\hline & & & & \\
\hline Hansen J Statistic & 0.083 & 0.069 & 0.066 & 0.053 \\
\hline Hansen J p-value & 0.773 & 0.792 & 0.797 & 0.818 \\
\hline \multicolumn{5}{|l|}{ Test of endogeneity } \\
\hline C Test Statistic & 0.026 & 0.011 & 3.018 & 2.945 \\
\hline $\mathrm{C}$ Test p-value & 0.873 & 0.916 & 0.083 & 0.086 \\
\hline $\mathrm{R}^{2}$ & 0.717 & 0.735 & 0.706 & 0.724 \\
\hline Observations & 16478 & 16478 & 16478 & 16478 \\
\hline
\end{tabular}

$* * * \mathrm{p}<0.01, * * \mathrm{p}<0.05, * \mathrm{p}<0.1$. Cluster-robust standard errors in parentheses.

Control dummies are included but not reported.

34 